\title{
Penile rehabilitation with a vacuum erectile device in an animal model is related to an antihypoxic mechanism: blood gas evidence
}

\author{
Hao-Cheng Lin ${ }^{1,2}$, Wen-Li Yang ${ }^{3}$, Jun-Lan Zhang ${ }^{3}$, Yu-Tian Dai ${ }^{1}$ and Run Wang,
}

Our previous study showed that vacuum erectile device (VED) therapy has improved erectile function in rats with bilateral cavernous nerve crush (BCNC) injuries. This study was designed to explore the mechanism of VED in penile rehabilitation by analyzing cavernous oxygen saturation $\left(\mathrm{SO}_{2}\right)$ and to examine the effect of VED therapy on preventing penile shrinkage after BCNC. Thirty adult SpragueDawley rats were randomly assigned into three groups: group 1 , sham surgery; group 2, BCNC; and group 3, BCNC+VED. Penile length and diameter were measured on a weekly basis. After 4 weeks of therapy, the penile blood was extracted by three methods for blood gas analysis (BGA): method 1, cavernous blood was aspirated at the flaccid state; method 2, cavernous blood was aspirated at the traction state; and method 3, cavernous blood was aspirated immediately after applying VED. $\mathrm{SO}_{2}$ values were tested by the blood gas analyzer. The results showed that VED therapy is effective in preventing penile shrinkage induced by BCNC (Penile shortening: BCNC group $1.9 \pm 1.1 \mathrm{~mm}$; VED group $0.3 \pm 1.0 \mathrm{~mm} ; P<0.01$. Penile diameter reduction: $B C N C$ group $0.28 \pm 0.14 \mathrm{~mm}$; VED group $0.04 \pm 0.14 \mathrm{~mm} ; P<0.01)$. The mean $\mathrm{SO}_{2} \pm$ s.d. values were increased by VED application $(88.25 \% \pm 4.94 \%)$ compared to the flaccid $(76.53 \% \pm 4.16 \%)$ or traction groups $(78.93 \% \pm 2.56 \%)(P<0.05)$. The calculated blood constructs in the corpus cavernosum right after VED application were $62 \%$ arterial and $38 \%$ venous blood. These findings suggest that VED therapy can effectively preserve penile size in rats with BCNC injury. The beneficial effect of VED therapy is related to antihypoxia by increasing cavernous blood $\mathrm{SO}_{2}$. Asian Journal of Andrology (2013) 15, 387-390; doi:10.1038/aja.2013.18; published online 8 April 2013

Keywords: blood $\mathrm{SO}_{2}$; erectile dysfunction (ED); penile size; vacuum therapy

\section{INTRODUCTION}

Currently, prostate cancer is the most common solid organ cancer in men, ${ }^{1}$ and radical prostatectomy (RP) is a commonly used surgical treatment for localized prostate cancer. ${ }^{2}$ Many patients suffer from erectile dysfunction (ED) and penile shrinkage after RP. Fraiman et al. ${ }^{3}$ reported that there was a decrease in all penile dimensions after nervesparing RP. The flaccid and erect measurements of length and circumference decreased $8 \%$ and $9 \%$, respectively, after surgery. The most substantial change occurred between the first 4 and 8 months postoperatively. Munding et al. ${ }^{4}$ showed that the stretched penile length decreases after RP at 3 months of follow-up in most men; $48 \%$ had considerable shortening greater than $1.0 \mathrm{~cm}$. Savoie et al. ${ }^{5}$ evaluated penile length 3 months after RP in a prospective study and found a significant decrease in the flaccid, stretched and circumferential measurements of the penis.

Vacuum erectile device (VED) therapy utilizes negative pressure to distend the corporal sinusoids and to increase blood inflow to the penis. Numerous publications have suggested that VED therapy improves erectile function in $84 \%-95 \%$ of patients. ${ }^{6-9}$ Recently, VED therapy has become the second most commonly used modality for penile rehabilitation. ${ }^{10}$ Studies suggest that vacuum therapy may preserve penile length, improve the sexual satisfaction of the patient and partner and allow the earlier return of spontaneous erections. ${ }^{2,11,12}$ However, there is no basic scientific evidence demonstrating that VED therapy prevents penile shrinkage after $\mathrm{RP}$, and the mechanism of VED for penile rehabilitation after RP is not clear.

Our hypothesis for VED in penile rehabilitation is that artificial erections shortly after RP facilitate tissue oxygenation, reduce cavernosal fibrosis and decrease apoptosis; therefore, the penile integrity is preserved, and the erectile functions can recover when the cavernosal nerve function returns. Previously, we designed a rat-specific VED to study the VED therapy for ED in rats with bilateral cavernous nerve crush (BCNC) injuries. ${ }^{13}$ Our data showed that VED therapy preserves erectile function through antihypoxic, antiapoptotic and antifibrotic mechanisms. ${ }^{11}$ Our previous work was limited by the fact that we did not have data on penile size with VED therapy or direct evidence of the oxygen levels in the rat penis after VED application. Thus, the objectives of this study were to assess the effect of VED therapy on the preservation of penile length and circumference after BCNC and to measure the oxygen level in the rat penis after VED application. 


\section{MATERIALS AND METHODS}

\section{Materials}

Sprague-Dawley rats were purchased from Harlan Laboratories (Indianapolis, IN, USA). The Radiometer ABL80 Flex Blood gas analyzer was from Radiometer Medical ApS (Bronshoj, Denmark), and the Origin 6.1 was obtained from OriginLab Corporation (Northampton, MA, USA). All animal procedures were approved by our institutional Animal Welfare Committee.

\section{Methods}

Penile length and circumference preservation. The BCNC animal model was used to mimic ED after RP. ${ }^{14}$ Briefly, the rats were anesthetized, shaved and disinfected as required. They were placed in a supine position. A midline suprapubic incision was made to expose the bladder and prostate. The major pelvic ganglion was isolated after carefully separating any overlying adipose tissues. Cavernous nerves were isolated and identified. At the point of $5 \mathrm{~mm}$ distal to the major pelvic ganglion, the bilateral cavernous nerves were crushed using an ultrafine hemostat with full tip closure for $30 \mathrm{~s}$, removed for $30 \mathrm{~s}$ and then reapplied for another $30 \mathrm{~s}$. The incision was closed with 3-0 Vicryl sutures. Analgesia and antibiotics were applied before and after the operation as required.

Thirty Sprague-Dawley rats (male, 200-224 g) were randomized into three groups: group 1 ( $\operatorname{sham}, n=10$ ), sham surgery, no cavernous nerve crush; group 2 (BCNC, $n=10)$, surgery with BCNC, but no therapy; and group 3 (BCNC+VED therapy, $n=10)$, surgery with BCNC and the VED used for 5 min twice daily, Monday to Friday from day 10. Penile length and diameter were measured on a weekly basis. The rats were anesthetized by isoflurane inhalation and placed in a supine position. A tension meter was applied to maintain the same tension (Figure 1a). Penile length was measured from the pubic bone to the tip of the penis with the vernier caliper (Figure 1b). Penile diameter was measured at the middle shaft with the vernier caliper (Figure 1c). Penile diameter and length measurements were obtained by the same person to minimize differences.

Blood gas evidence of VED application. The same animal groups were observed or treated with VED for 4 weeks. Rat penile blood was drawn for blood gas analysis (BGA) by the Radiometer ABL80 Flex Blood gas

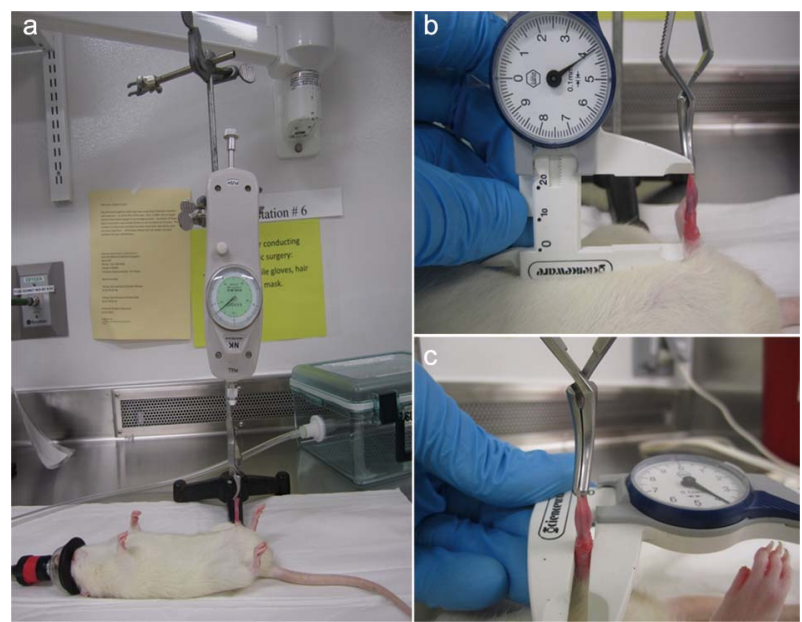

Figure 1 (a) The tension meter was applied to maintain the same tension; (b) the vernier caliper was used for the penile length measurement; (c) the vernier caliper was used for the penile diameter measurement. analyzer (Figure 2). Penile blood was extracted by three methods for BGA: method 1, cavernous blood was aspirated at the state of flaccidity; method 2, cavernous blood was aspirated at the state of traction; and method 3, cavernous blood was aspirated immediately after applying VED. Penile blood was extracted using a $1 / 2 \mathrm{ml}$ insulin syringe with $400 \mathrm{IU} \mathrm{ml}^{-1}$ heparin. Blood samples were stored in the $125-\mu \mathrm{l}$ blood gas capillary tubes at $4{ }^{\circ} \mathrm{C}$ for less than $30 \mathrm{~min} .{ }^{15}$ From each animal, $100 \mu \mathrm{l}$ blood was collected for blood gas testing.

\section{Statistical analysis}

All measurements are expressed as the mean \pm s.d. Data were analyzed using $t$-test or analysis of variance with Origin 6.1 for multiple comparisons among groups. $P<0.05$ was considered statistically significant.

\section{RESULTS}

VED therapy is effective in preventing penile shortening induced by BCNC

Weekly measurements of penile length started at 10 days after BCNC. Only the data collected on day 1 and day 42 were used for calculation (penile length at day 42 minus penile length at day 1). Penile shortening was observed in the BCNC group, compared to the sham and the BCNC with VED treatment groups $(P<0.01)$. Additionally, the penile shortening $(1.9 \pm 1.1 \mathrm{~mm})$ in the BCNC group was statistically significant compared to baseline $(P<0.01)$, while no significant penile shortening was observed in sham $(-0.2 \pm 1.4 \mathrm{~mm})$ or BCNC+VED therapy groups $(0.3 \pm 1.0 \mathrm{~mm})(P>0.05)$ (Table 1$)$.

\section{VED therapy is effective in preventing penile circumference reduction}

Penile diameter was used to estimate the penile circumference for simplicity in the measurement of rat penis. No penile diameter reductions were observed in the VED therapy $(0.04 \pm 0.14 \mathrm{~mm})$ or sham groups $(-0.03 \pm 0.12 \mathrm{~mm})(P>0.05)$. Decreased penile diameters were found in the BCNC without VED group $(0.28 \pm 0.14 \mathrm{~mm})$ compared to the baseline, sham and VED-treated groups $(P<0.01)$ (Table 2).

VED application increases the oxygen saturation $\left(\mathrm{SO}_{2}\right)$ level in penile cavernous

BCNC rats were repeatedly used for blood gas analysis. Six validated blood samples were collected for venous and arterial measurements;

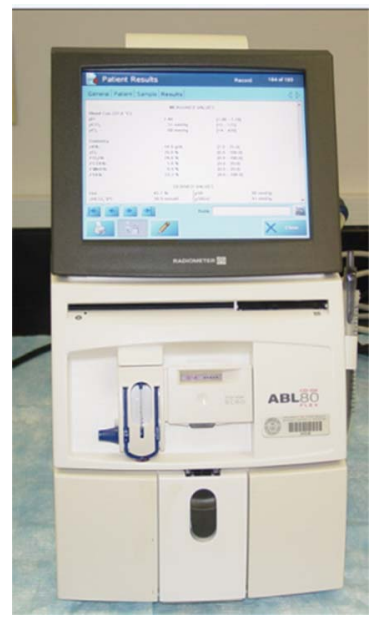

Figure 2 The Radiometer ABL80 Flex Blood gas analyzer. 
Table 1 VED therapy is effective in preventing penile shortening induced by BCNC

\begin{tabular}{|c|c|c|c|c|}
\hline Group & Number & Penile length at day 1 (mean \pm s.d.) (mm) & 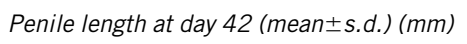 & Penile shortening (mean \pm s.d.) $(\mathrm{mm})$ \\
\hline Sham & 10 & $24.4 \pm 1.0$ & $24.6 \pm 1.0$ & $-0.2 \pm 1.4$ \\
\hline $\mathrm{BCNC}$ & 10 & $25.0 \pm 0.9$ & $23.0 \pm 1.1 *$ & $1.9 \pm 1.1 * \#$ \\
\hline $\mathrm{BCNC}+\mathrm{VED}$ & 10 & $24.8 \pm 1.3$ & $24.5 \pm 1.4$ & $0.3 \pm 1.0$ \\
\hline
\end{tabular}

Abbreviations: BCNC, bilateral cavernous nerve crush; VED, vacuum erectile device.

$* P<0.01$ compared with the sham group.

${ }^{\#} P<0.01$ compared with the BCNC+VED therapy group.

$* P<0.01$ compared with day 1 .

Table 2 VED therapy is effective in preventing penile circumference reduction

\begin{tabular}{|c|c|c|c|c|}
\hline Group & Number & Penile diameter at day 1 (mean土s.d.) (mm) & Penile diameter at day $42($ mean \pm s.d.) $(\mathrm{mm})$ & Penile diameter reduction (mean \pm s.d.) $(\mathrm{mm})$ \\
\hline Sham & 10 & $3.87 \pm 0.21$ & $3.91 \pm 0.13$ & $-0.03 \pm 0.12$ \\
\hline $\mathrm{BCNC}$ & 10 & $3.90 \pm 0.23$ & $3.61 \pm 0.20 \%$ & $0.28 \pm 0.14^{* \#}$ \\
\hline $\mathrm{BCNC}+\mathrm{VED}$ & 10 & $3.91 \pm 0.22$ & $3.86 \pm 0.16$ & $0.04 \pm 0.14$ \\
\hline
\end{tabular}

Abbreviations: BCNC, bilateral cavernous nerve crush; VED, vacuum erectile device.

$* P<0.01$ compared with the sham group.

${ }^{\#} P<0.01$ compared with the BCNC+VED therapy group.

* $P<0.01$ compared with day 1 .

and eight validated blood samples were collected for the flaccid, traction and VED application groups. The results were summarized in Table 3. The mean $\mathrm{SO}_{2} \pm$ s.d. values were increased by VED application $(88.25 \% \pm 4.94 \%)$ compared to the flaccid $(76.53 \% \pm 4.16 \%)$ or the traction group $(78.93 \% \pm 2.56 \%)(P<0.05)$. No obvious differences were found between the flaccid group and the traction group $(P>0.1)$. The arterial blood percentage $(A \%)$ in the corpus cavernosum was calculated by the following formula: $A \%=$ [Measured $\mathrm{SO}_{2}-V$ $\left.\left(\mathrm{SO}_{2}\right)\right] /\left[A\left(\mathrm{SO}_{2}\right)-V\left(\mathrm{SO}_{2}\right)\right]$. The venous blood percentage $(V \%)$ in the corpus cavernosum was calculated by the following formula: $V \%=1-A \%$. The calculated blood constructs in the corpus cavernosum right after VED application were $62 \%$ arterial and $38 \%$ venous blood. The calculated blood constructs in the corpus cavernosum under traction were $27 \%$ arterial and $73 \%$ venous blood. The calculated blood constructs from the flaccid corpus cavernosum were $12 \%$ arterial and $88 \%$ venous blood (Figure 3).

\section{DISCUSSION}

Penile shortening after RP is common. ${ }^{3-5}$ Vasconcelos et al. ${ }^{16}$ showed that nearly $1 \mathrm{~cm}$ of penile shortening after RP may be expected up to 12 months. Our data supported these clinical findings. Our study showed that penile shortening can be seen as early as 7 days after BCNC and that penile length and diameter shortening were significant compared to the baseline or sham group 4 weeks after BCNC. User et al. ${ }^{17}$ showed that penile wet weight was significantly decreased at each time point after bilateral cavernous nerve transection in animal studies. Additionally, there are clinical data showing that the VED user has fewer complaints of penile shortening. Kohler et al. ${ }^{6}$ conducted a multicenter randomized study to compare early ( 1 month post-nerve sparing RP) to traditional (6 months after surgery) use of VED. Preliminary results showed that the early use of VED for rehabilitation significantly improves the IIEF-EF scores and preserves penile length compared to control group. Raina et al. ${ }^{12}$ found $17 \%$ vs. $11 \%$ recovery of erectile function with daily use of VED; and 23\% VED users $v$ s. $85 \%$ non-VED users reported penile shrinkage compared with controls in a 9-month study with total of 109 patients who underwent nerve-sparing or non-nerve-sparing RP. Our animal study provided the first scientific evidence in an animal model that VED therapy started at day 10 after BCNC could effectively preserve the penile length and girth in BCNC rats.

Bosshardt et al. ${ }^{18}$ found that the mean $\mathrm{O}_{2}$ saturation of corporeal blood immediately after VED-induced erection was $79.2 \%$. Of the blood in a VED-induced erection, $58 \%$ was arterial, and $42 \%$ was venous in origin. However, currently, many clinicians have an

Table 3 Oxygen saturation in veins, arteries, the flaccid penis, the penis with traction and VED use

\begin{tabular}{lcc}
\hline Group & Rat number & $\mathrm{SO}_{2}$ (mean \pm s.d.) (\%) \\
\hline Vein (veno cava) & 6 & $71.33 \pm 2.38$ \\
Artery (coratid) & 6 & $98.28 \pm 2.69$ \\
Flaccidity penis & 8 & $76.53 \pm 4.16$ \\
Penis with traction & 8 & $78.93 \pm 2.56$ \\
VED use & 8 & $88.25 \pm 4.94^{* \#}$ \\
\hline
\end{tabular}

Abbreviation: VED, vacuum erectile device.

$* P<0.05$ compared with the flaccid penis group.

\# $P<0.05$ compared with the penis with traction group.

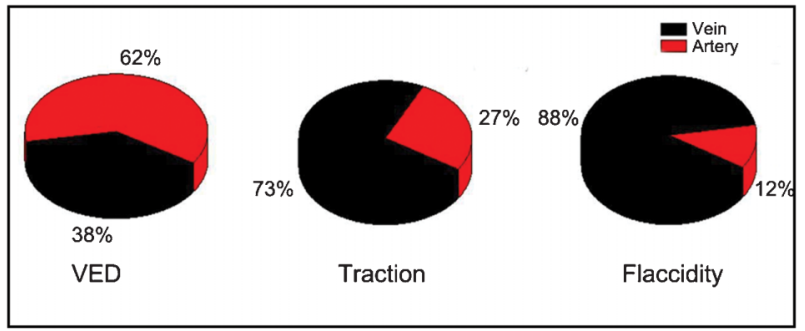

Figure 3 The blood composition in the corpus cavernosum by the following formula: $A \%=\left[\right.$ Measured $\left.\mathrm{SO}_{2}-V\left(\mathrm{SO}_{2}\right)\right] /\left[A\left(\mathrm{SO}_{2}\right)-V\left(\mathrm{SO}_{2}\right)\right] ; V \%=1-A \%$. VED therapy group: arterial blood accounts for $62 \%$, and venous blood accounts for $38 \%$ in the corpus cavernosum. Traction group: arterial blood accounts for $27 \%$, and venous blood accounts for $73 \%$ in the corpus cavernosum. Flaccid group: arterial blood accounts for $12 \%$, and venous blood accounts for $88 \%$ in the corpus cavernosum. VED, vacuum erectile device. 
incorrect perception that VED provides only venous blood to the penis. Our previous study showed that one of the mechanisms of VED therapy in preserving erectile function was through antihypoxic effects, as shown by the decrease in hypoxia-inducible factor- $1 \alpha{ }^{11}$ Our current blood gas results provide direct evidence that VED therapy increased penile oxygen levels compared to controls. In our study, the mean $\mathrm{SO}_{2} \pm$ s.d. values were increased by VED application compared to the flaccid or traction groups. Erection induced by VED is largely due to the arterial blood inflow; it was calculated in our study that $62 \%$ of the blood is arterial in origin, compared to only $27 \%$ by traction and $12 \%$ in a flaccid state.

Increased tissue oxygen effectively alleviates the tissue hypoxia damage caused by cavernous nerve injuries. This may also inhibit tissue cell apoptosis and prevent cavernosal tissue fibrosis. As shown in our previous study, VED can prevent apoptosis and fibrosis. Additionally, arterial blood may not only provide oxygen to the corporal tissues, but it may also carry other nutrients, such as certain growth factors, to the tissues for the benefit of penile recovery. This hypothesis should be confirmed in future studies.

\section{CONCLUSION}

Our study shows that VED therapy can effectively preserve penile size in rats with BCNC injuries. The beneficial effect of VED therapy is related to antihypoxia by increasing the cavernous blood $\mathrm{SO}_{2}$.

\section{AUTHOR CONTRIBUTIONS}

HCL, RW and YTD contributed to the concept and design of the study and drafted and revised the manuscript. HCL, WLY and JLZ contributed through the performance of experiments, the acquisition and the analysis of data. All authors read and approved the final manuscript version.

\section{COMPETING FINANCIAL INTERESTS}

Run Wang is the investigator of The American Medical System, Inc., Coloplast Inc., Vivus, Inc., Timm Medical, Inc. and UroMatrix Medical Systems, and the consultant of Coloplast Inc., Timm Medical, Inc. and MenMD, Inc.

\section{ACKNOWLEDGMENTS}

The authors would like to thank Ms Dorothy Stradinger for her editorial assistance. This study was funded in part by unlimited education/research grants from UroMatrix Medical Systems and Timm Medical, Inc.

1 Siegel R, Naishadham D, Jemal A. Cancer statistics, 2012. CA: Cancer J Clin 2012; 62: 10-29.

2 Wang R. Penile rehabilitation after radical prostatectomy: where do we stand and where are we going? J Sex Med 2007; 4: 1085-97.

3 Fraiman MC, Lepor H, McCullough AR. Changes in penile morphometrics in men with erectile dysfunction after nerve-sparing radical retropubic prostatectomy. Mol Urol 1999; 3: 109-15.

4 Munding MD, Wessells HB, Dalkin BL. Pilot study of changes in stretched penile length 3 months after radical retropubic prostatectomy. Urology 2001; 58: 567-9.

5 Savoie M, Kim SS, Soloway MS. A prospective study measuring penile length in men treated with radical prostatectomy for prostate cancer. J Urol 2003; 169: 1462-4.

6 Kohler TS, Pedro R, Hendlin K, Utz W, Ugarte R et al. A pilot study on the early use of the vacuum erection device after radical retropubic prostatectomy. BJU Int 2007; 100: 858-62.

7 Turner LA, Althof SE, Levine SB, Bodner DR, Kursh ED et al. External vacuum devices in the treatment of erectile dysfunction: a one-year study of sexual and psychosocial impact. J Sex Marit Ther 1991; 17: 81-93.

8 Cookson MS, Nadig PW. Long-term results with vacuum constriction device. J Urol 1993; 149: 290-4.

9 Zippe CD, Raina R, Thukral M, Lakin MM, Klein EA et al. Management of erectile dysfunction following radical prostatectomy. Curr Urol Rep 2001; 2: 495-503.

10 Tal R, Teloken $P$, Mulhall JP. Erectile function rehabilitation after radical prostatectomy: practice patterns among AUA members. J Sex Med 2011; 8: 2370-6.

11 Yuan J, Lin H, Li P, Zhang R, Luo A et al. Molecular mechanisms of vacuum therapy in penile rehabilitation: a novel animal study. Eur Urol 2010; 58: 773-80.

12 Raina R, Agarwal A, Ausmundson S, Lakin M, Nandipati KC et al. Early use of vacuum constriction device following radical prostatectomy facilitates early sexual activity and potentially earlier return of erectile function. Int J Impot Res 2006; 18: 77-81.

13 Yuan J, Westney OL, Wang R. Design and application of a new rat-specific vacuum erectile device for penile rehabilitation research. J Sex Med 2009; 6: 3247-53.

14 Mullerad M, Donohue JF, Li PS, Scardino PT, Mulhall JP. Functional sequelae of cavernous nerve injury in the rat: is there model dependency. J Sex Med 2006; 3: 77-83.

15 Knowles TP, Mullin RA, Hunter JA, Douce FH. Effects of syringe material, sample storage time, and temperature on blood gases and oxygen saturation in arterialized human blood samples. Respir Care 2006; 51: 732-6.

16 Vasconcelos JS, Figueiredo RT, Nascimento FL, Damiao R, da Silva EA. The natural history of penile length after radical prostatectomy: a long-term prospective study. Urology 2012; 80: 1293-7.

17 User HM, Hairston JH, Zelner DJ, McKenna KE, McVary KT. Penile weight and cell subtype specific changes in a post-radical prostatectomy model of erectile dysfunction. J Urol 2003; 169: 1175-9.

18 Bosshardt RJ, Farwerk R, Sikora R, Sohn M, Jakse G. Objective measurement of the effectiveness, therapeutic success and dynamic mechanisms of the vacuum device. Br J Urol 1995; 75: 786-91. 